\title{
Decline of sea-ice in the Greenland Sea intensifies extreme precipitation over Svalbard
}

\author{
Malte Müller ${ }^{\mathrm{a}, \mathrm{b}, *}$, Timo Kelder ${ }^{\mathrm{c}}$, Cyril Palerme ${ }^{\mathrm{a}}$ \\ ${ }^{a}$ Norwegian Meteorological Institute, Oslo, Norway \\ ${ }^{b}$ Department of Geosciences, University of Oslo \\ ${ }^{c}$ Loughborough University, Loughborough, UK
}

\begin{abstract}
Extreme precipitation over the Svalbard Archipelago in the Arctic can have severe consequences for the ecosystem and society. In recent years several extreme precipitation events have been observed at Ny Ålesund, a weather station in the north-western part of the Svalbard Archipelago. The most recent observed events in the years 2012, 2016, and 2018 were the highest events in the entire precipitation record from 1974 till today. The key question of our study is whether those recently observed extremes are part of a climate change signal or are a random accumulation of extremes. With a novel approach based on a large ensemble of model simulations, we show that the likelihood of occurrence for extreme precipitation over Svalbard has increased over the last four decades. We find that the likelihood of occurrence is connected to the sea ice extent east of Greenland because the presence of sea ice shields the west coast of Svalbard from the incoming southerly moist air. Our analysis suggests, that in the future with a further decline of the sea ice coverage east of Greenland, the recently observed precipitation extremes will become even more frequent.
\end{abstract}

Keywords:

\section{Introduction}

Sea-ice declined rapidly over the last decades in many Arctic regions (Ser3 reze and Stroeve, 2015; Stroeve and Notz, 2018). Due to its reflective and

\footnotetext{
*Corresponding author

Email address: maltem@met.no (Malte Müller )
} 
4

insulating properties in the coupled atmosphere-ice-ocean system it has an important role in Earth's climate (Screen and Simmonds, 2010; Vihma, 2014). In particular, for the sea-ice extent in the North Atlantic sector a number of studies found connections to the strength and position of the stratospheric polar vortex (Kim et al., 2014; Zhang et al., 2016), to the wintertime cyclone track (Magnusdottir et al., 2004; Inoue et al., 2012; Rinke et al., 2017), to the frequency of European blocking (Ruggieri et al., 2016), and to cold winter extremes over northern continents (Petoukhov and Semenov, 2010). However, there were only a few years with very low sea-ice conditions, and thus the small sample size makes it difficult to confidently attribute sea-ice loss to specific changes in the weather characteristics (Vihma, 2014; Cohen et al., 2014).

While there are indications of seasonal trends in polar moisture transport (Rinke et al., 2019), it still remains uncertain why and to which extent Arctic mean and extreme precipitation is changing in our warming climate (Vihma et al., 2016). The extremes are caused by the transport of moisture across large spatial scales, embedded in a predominantly southerly flow, and often characterized as 'atmospheric rivers' (ARs)(Serreze et al., 2015). It has been shown that the ARs are the main source of poleward water vapor transport, they are explaining up to $73 \%$ of the precipitation variance north of $70^{\circ} \mathrm{N}$ and are thus a key factor in understanding the polar hydroclimate (Nash et al., 2018). The major pathways of the ARs are through the Atlantic and Pacific sector, while the Atlantic dominates in particular at latitudes higher than $70^{\circ} \mathrm{N}$. Besides the importance for the polar water budget, the extreme precipitation events can have a strong impact on the eco-system and people living on the Svalbard Archipelago (Hansen et al., 2014).

Only very few historical long-term observations for precipitation exist for the Arctic region and thus it is not possible to understand recent changes in the extreme precipitation characteristics from observations alone (Serreze et al., 2015). We are applying a novel approach to utilize a large ensemble hindcast of a coupled and high-resolution atmosphere-ice-ocean model to determine recent trends in extreme weather (Kelder et al., 2020). The hindcast is from the ECMWF (European Centre for Medium-Range Weather Forecasts) seasonal prediction system SEAS5 (Johnson et al., 2019) and is initialised from atmospheric and oceanic reanalysis data. A first study of this large-ensemble data-set demonstrated that the uncertainties of the extreme value estimates and trends can be greatly reduced (Kelder et al., 2020). They showed that over the Svalbard area the 100-year return value for extreme pre- 
cipitation changed from 1981 to 2015 by about 8\% (Kelder et al., 2020). In the present study, we have a specific focus on the underlying processes which are the drivers for changes in extreme Arctic precipitation. The precipitation extremes over the Svalbard Archipelago are analysed in connection with the sea-ice extent east of Greenland, atmospheric states represented by the $500 \mathrm{hPa}$ geopotential height (G500) and the mean sea level pressure, as well as the precipitation-evaporation fields.

\section{Data and Methods}

\subsection{Observations and the global atmospheric reanalysis ERA5.}

The in situ observations are from four precipitation gauges on the Svalbard Archipelago and provided by the Norwegian Meteorological Institute. The Ny Ålesund and Longyearbyen (official name Svalbard Lufthavn) are complete records with daily values from 1981 till 2018. The record of Hornsund covers the years from 1996 till 2018 and precipitation data from Sveagruva is available from 1981 till 2001.

ERA5 is an atmospheric reanalysis which utilizes cycle 41r2 of ECMWF's Integrated Forecast System (IFS), with a horizontal T639 resolution (approx. $36 \mathrm{~km}$ resolution) and 137 vertical levels. We utilize hourly values of precipitation gridded on a 1440x720 regular grid and accumulated daily values from 1981 to 2018. The hourly precipitation values from the first 12 hours of the short forecast with initial time at 06 and 12UTC are used. In addition, the integrated water vapour transport is calculated from 6-hourly instantaneous moisture and horizontal wind variables of all 137 levels. In ERA5 sea-ice is prescribed from 1979 to 2007 by the HadISST2 (Titchner and Rayner, 2014) and from 2007 to 2018 by the OSTIA (Donlon et al., 2012) satellite products (Hirahara et al., 2016).

\subsection{A large ensemble for the present-climate from SEAS5 re-forecasts.}

SEAS5 is a coupled ocean, sea-ice, and atmosphere seasonal forecasting system (Johnson et al., 2019). The atmospheric component is based on cycle 43r1 of the ECMWF-IFS, has 91 vertical levels and a spectral horizontal resolution of T319. The grid spacing of the physical space, where the model's physical parameterisations are calculated, is approximately $36 \mathrm{~km}$. The ocean model NEMO (Nucleus for European Modelling of the Ocean and sea-ice model LIM2 (Louvain-la-Neuve Sea Ice Model) have a horizontal resolution of 0.25-degree (Madec et al., 2016; Fichefet and Maqueda, 1997). The 
atmosphere is initialized by ERA-Interim (Dee et al., 2011) and the ocean and sea-ice components are initialized by the OCEAN5 (Zuo et al., 2018) reanalysis.

The re-forecast and forecast (simply referred to as forecasts in the following) data set of SEAS5 consists of monthly 25-ensemble member forecasts with lead times up to 7 months for the years from 1981 to present. Each of the forecasts are starting on the first of the month and we are utilizing all forecasts starting on the first of July through October and the forecasted periods covering the season from November to January. Hence, we obtain 100 seasonal weather realizations for each year between 1981 and 2018, or in total 3800 seasons, representing the climate of the past 38 years (Kelder et al., 2020).

We generally assume that precipitation events are not predictable more than about two weeks in advance because of the chaotic nature of the atmospheric system (Lorenz, 1969). We do not use the first month of the seasonal forecasts, in order to avoid, due to predictability constraints, clustering of weather extremes. However, extreme precipitation events might cluster beyond this horizon because of the underlying slow-varying components of the atmosphere-ocean system. To assess to what extent clustering of extreme precipitation events is taking place, we test how much the precipitation extremes over the years correlate between the ensemble members. We calculate the spearman $\rho$ statistic between each independent pair of ensemble members, resulting in $300 \rho$ values for each lead time. To test the significance of the correlations, a permutation test is performed with $n=10.000$. We find that the extreme event data set can be considered independent for both regions (Fig. 1a). See Kelder et al. (2020) for more details on this method.

\subsection{Comparison of SEAS5 and ERA5 precipitation maxima.}

In order to define the area for our analysis of extreme precipitation we are utilizing the 98th percentile of seasonal (NDJ) daily precipitation of ERA5 for the period from 1981 to 2018. The area at the west coast of Svalbard where values exceed $15 \mathrm{~mm} /$ day is defined as the study area over which precipiation values are average for the following extreme precipitation analysis (red contour line in Fig. 2b).

The ERA5 data set provides 38 seasonal (NDJ) precipitation maxima from 1981 till 2018. The data set of SEAS5 covers the same years but with 100 times more realizations. We find that most of the ERA5 extremes fall within the range of SEAS5 simulated extremes (Fig.1b). In order to further 
compare the statistical characteristics between the two data sets, we sample 38 data points selected from all 3800 data points of SEAS5 and repeat this 10 thousand times. For each bootstrapped timeseries, we calculate the mean, standard deviation, skewness and kurtosis. From all bootstrapped values, the SEAS5 95\% confidence intervals of the distribution characteristics are calculated. The SEAS5 confidence intervals are compared to the values obtained from ERA5. For further explanation of the method we refer to Thompson et al. (2017).

We perform this test on the raw SEAS5 extreme precipitation and on a bias-corrected SEAS5 extreme precipitation data set. The bias correction is a simple scaling of SEAS5 to ERA5, where we use a constant ratio between the mean of ERA5 and SEAS5 NDJ precipitation maxima, i.e. a bias correction factor of 1.34 for the northwest Svalbard region. After bias correction, we find that the statistical characteristics, i.e. the mean, standard deviation, skewness and kurtosis, fall within the 95\% confidence intervals of SEAS5 (not shown). We apply this simple scaling in order to keep the sea-ice to precipitation relationship the same, which would be distorted with commonly applied (uni-variate) quantile-mapping approaches (Cannon et al., 2020). The ratio between ERA5 and SEAS5 mean and median extreme precipitation events does not influence the scaling by more than $5 \%$.

\subsection{General Extreme Value statistical approach.}

The General Extreme Value Distribution (GEV) is fitted to seasonal precipitation maxima obtained from the SEAS5 and ERA5 model systems. The cumulative distribution function of the GEV is

$$
F(x)=\exp \left[-\left(1+\xi\left(\frac{x-\mu}{\sigma}\right)\right)^{-\frac{1}{\xi}}\right],\left(1+\xi\left(\frac{x-\mu}{\sigma}\right)\right)>0
$$

where $\mu$ is the location, $\sigma$ the scale, and $\xi$ the shape parameter(Coles et al., 2001). In order to obtain the parameters of the GEV distribution the Maximum Likelihood Estimation methods is used and the $95 \%$ confidence intervals of GEV distributions are calculated based on normal approximation. The computations have been performed by utilizing the extRemes package (Gilleland et al., 2016) in R.

The GEV analysis is performed for either all the data from SEAS5 and ERA5 for a respective region, or the data is subdivided into events which occurred during a specific sea-ice coverage. This sea-ice coverage is computed 
for the region R1 (Fig.2b) and defined as the area (in \%) covered by sea-ice ice concentration larger than $15 \%$ at the same day of the event.

\section{Svalbard precipitation observations and reanalysis}

We analyse precipitation observations from the four weather stations at Ny Ålesund, Sveagruva, Hornsund, and Longyearbyen located on the Svalbard Archipelago (Fig.3). Generally, most of the extremes occur in the fall period from November to January (in the following we are referring to the NDJ season). Analyzing the seasonal NDJ extreme precipitation at those stations shows that the largest event within each station has been observed in the last 8 years. Those largest events greatly exceed the magnitudes from the ones observed before 2012. For example at Ny Ålesund the three most extreme precipitation events between 2012 and 2018 are 66, 87, and $98 \mathrm{~mm} /$ day, while all the extremes before 2012 are below $57 \mathrm{~mm} /$ day.

In order to advance our understanding of the spatial characteristics of extreme precipitation over the Svalbard Archipelago we utilize the ERA5 atmospheric reanalysis (Hersbach et al., 2018). First, we analyse the reanalysis' capability to simulate the extreme precipitation events by comparing the reanalysis at the grid-cell closest to the respective observation station for the entire available observation records between 1979 and 2018. In general, the reanalysis reproduces the extreme precipitation events but underestimates the point-observed precipitation extremes (Fig. 4). However, comparing a point observation to a relatively coarse resolution model in complex terrain is challenging. For example, in the case of the November 2016 event, where a precipitation maximum of $87 \mathrm{~mm} /$ day was observed in Ny Alesund, the maximum precipitation at the represented grid cell is $48 \mathrm{~mm}$, and a local maximum of $63 \mathrm{~mm}$ is simulated in a distance of about $100 \mathrm{~km}$ (Fig. 2). Concluding from these comparisons, we consider ERA5 useful for further study of these type of precipitation extreme events, but the total precipitation values have to be taken with care and a further downscaling or correction would be necessary for the use in impact studies.

The extreme precipitation events are directly connected to the southerly moisture flow (Serreze et al., 2015; Nash et al., 2018). For example, during the extreme event in November 2016 which was the largest event in the record for Longyearbyen, a considerable amount of moisture was transported towards the west coast of Svalbard, with subsequent precipitation due to the orographic uplift (Fig.2). In the following, we are using the area at the 
northwest coast of Svalbard which is most affected by those extremes (red contour line in Fig.2b).

\section{Frequency of extreme precipitation and its relation to sea-ice extent}

We utilize an ensemble hindcast of ECMWF seasonal prediction system SEAS5 (Johnson et al., 2019) to explain physical drivers of recent changes in Arctic extreme precipitation. SEAS5 is a coupled atmosphere, ocean and sea-ice system with a spatial resolution of around $35 \mathrm{~km}$. Utilizing an resampling approach (e.g. Kelder et al., 2020) of the individual hindcasts provides 100 independent realizations from 1981 to 2018 (Sec. 2.2). We compute the spatially averaged northwest Svalbard seasonal NDJ maximum daily precipitation for ERA5 and all SEAS5 realizations (region denoted in Fig.2b). We find that SEAS5 precipitation extremes are underestimated compared to ERA5 and we apply a bias correction in order to allow for a meaningful comparison (Sec. 2.3).

First, assuming a stationary climate, we fit the General Extreme Value (GEV) distribution to SEAS5 and ERA5 (Sec. 2.4). Since we can assume that all the SEAS5 events are independent (Sec. 2.2), the increased sample size reduces the confidence intervals drastically compared to the single realization of ERA5 (Fig. 5a). The largest extreme precipitation events in ERA5 significantly deviate from the GEV fitted curve and the ERA5 related confidence intervals are becoming very large for return values larger than 10 years.

Second, we analyse the extreme events which occurred from 1981 to 1990 and from 2009 to 2018 (Fig. 5b). We observe a separation of the return values especially for larger return periods. However, the separation is relatively small. For example the event in 2016 is described with a 300 year return period in the present climate (2009 to 2018), and a 600 year return period in the time before 1990 .

Third, we divide the precipitation events according to the sea-ice coverage in the Greenland Sea, the region indicated in Fig.2a to study the link between sea-ice coverage and extreme precipitation over Svalbard. The largest four precipitation events within record and reanalysis, which deviate from the rest (Fig. 5a and c) occurred in 1993, 2012, 2016, and 2018 during years with low values for the sea-ice coverage in the Greenland Sea (29, 22, 22, and 23\%, respectively), which already suggests a link between the sea-ice extent east of Greenland and extreme precipitation over northwest Svalbard. However, 
only a few events have been observed which restrict robust detection of this link. The analysis of the SEAS5 large ensemble results in a statistically robust link between extreme precipitation and sea-ice coverage. When the sea-ice coverage is less than $15 \%$, an event of about $40 \mathrm{~mm}$ /day has a return period of 10 years, while in conditions with a sea-ice coverage of 15-50\% the return period increases to 30 years. The return period even increases up to 100 years for sea-ice extents of more than $50 \%$.

In the Greenland Sea the sea-ice coverage in the NDJ-season decreased over the last decade according to both ERA5 and SEAS5 (Fig. 6a). The seaice declined from about 30-60\% in the years 1980-2000 to values of around $20-30 \%$ in recent years (Fig. 6a). A strong change in the inter-seasonal variability occurring around 2005 is noteworthy, but we suspect that this characteristic stems from the switch-over of the sea-ice satellite product in 2007 in the ERA5 reanalysis (Hirahara et al., 2016).

\section{Composite analysis of extreme precipitation events}

The main characteristics of the large-scale atmospheric setup leading to extreme precipitation can be understood from a composite analysis of the largest events. For this analysis we are using all SEAS5 extreme events with precipitation amounts larger than the 20 year return value. While in reanalysis records this selection will only result in a few events, within SEAS5 there are in total 192 events. This large sample allows us to further divide the events into low and high sea-ice coverage in the Greenland Sea. Composite fields are then computed for G500, mean sea level pressure, precipitationevaporation, and sea-ice concentration (Fig. 8, 9, and Fig. 7).

The composite fields for the precipitation extremes in northwest Svalbard are characterized by low sea-level pressures located southeast of Greenland and between Svalbard and Greenland (Fig. S5). A positive anomaly in $500 \mathrm{hPa}$ height over Scandinavia and the Barents Sea and a negative anomaly over Greenland lead to a strong southerly flow of moisture directed towards the Svalbard Archipelago (Fig. 8). These characteristics have also been observed for the 2016 event (Fig. 2), as well as the 2012 and former extreme precipitation events (Serreze et al., 2015). During high sea-ice conditions over the Greenland Sea the $500 \mathrm{hPa}$ negative anomaly extends from the interior of Greenland into the ice-covered parts of the Greenland Sea. Instead, during low sea-ice conditions in the Greenland Sea the $500 \mathrm{hPa}$ negative anomaly is 
more confined to the interior of Greenland, which leads to a north-western shift of the pathway of the southerly flow.

The combined precipitation-evaporation fields reveal that during the extreme events a considerable amount of atmospheric moisture precipitates not only at the west coast of Svalbard but also in coastal areas in the south of Iceland and in the south-east of Greenland (Fig. 8a and b). In addition, over the Greenland Sea along the main axis of the southerly moisture transport the net precipitation-evaporation is positive (precipitation positive, evaporation negative). During the events with a large extent of sea-ice east of Greenland, higher precipitation-evaporation values are found over the Greenland Sea than for the events during a low sea-ice coverage.

During the events with large sea-ice coverage in the Greenland Sea the atmospheric moisture with its origin from lower latitudes is transported over sea-ice covered areas in the Greenland Sea. Due to the cold atmospheric surface layer over the sea-ice covered areas we can expect that the warm and moist air masses are lifted, which results in increased precipitation over the sea-ice (Komatsu et al., 2018). In addition, the sea-ice hinders the ocean surface water to evaporate. In total, both processes support a positive net precipitation-evaporation rate and a net loss of atmospheric moisture. This net loss reduces the total amount of moisture being transported to the northwest coast of Svalbard and thus can explain the smaller extreme precipitation rates when sea-ice extent east of Greenland is high.

Higher values of integrated water vapour (IWV) are found for events during low sea-ice conditions than for high sea-ice conditions, especially in the areas where the sea-ice cover varies the most, i.e. north of Iceland (Fig. 8c and d). This is consistent with the considerations of the previous paragraph and reflects the net loss of atmospheric moisture due to increased precipitation and decreased evaporation over the sea-ice.

We performed an additional assessment of the composite fields divided into events occurring between 1981 to 1990 and in the more recent period from 2010 to 2018 (Fig. 9). As expected from the analysis in Fig. 6a, it reveals that extreme events in the recent period have lower sea-ice than past ones (Fig. 9). This enhances the likelihood of more intense extreme events through the previously discussed changes in precipitation-evaporation and the IWV (Fig. 8c and d). However, the changes in precipitation-evaporation and IWV are not as clear over time as they are with changes in sea-ice extent (Fig. 8 and 9). This result is consistent with the extreme value analysis in the previous section. There the partitioning into extreme precipitation 
events during high and low sea-ice resulted in a clearer separation than the partitioning into past and present time periods (Fig. 5). Hence we conclude that the sea-ice extent east of Greenland describes more robustly than a trend over time the changes in the frequency of extreme precipitation over Svalbard.

\section{Summary and conclusions}

The reduction of the Arctic sea-ice extent over the last decades has a strong impact on the coupled atmosphere-ice-ocean system and the polar hydroclimate. The response of the atmosphere to low sea-ice events has been studied extensively (Vihma, 2014) and it has been shown that it leads locally to increased heat and moisture fluxes from the ocean to the atmosphere, decreased lower atmospheric static stability, and increased lower tropospheric heat and moisture content. In order to advance our understanding on the response of the atmospheric dynamics to the sea-ice loss, the separation from atmospheric internal variability is critical and thus, a large enough sample size is needed to reduce the signal-to-noise ratio (Screen et al., 2014).

We generated an ensemble data set of 3800 precipitation extreme events for an Arctic region on the Svalbard Archipelago. The archipelago is located in the Euro-Atlantic sector and represents one of the major gateways of moisture intrusion to the Arctic (Nash et al., 2018). We find that the return values of extreme precipitation increased steadily over the recent decades and that they are statistically connected to the extent of sea-ice in the Greenland Sea. In order to understand the processes driving extreme precipitation during low versus high sea-ice conditions, we perform a composite analysis of the atmospheric $500 \mathrm{hPa}$ geopotential height, mean sea level pressure, precipitation-evaporation, integrated water vapour, and sea ice concentration.

Our results of the composite analysis of the largest events indicate a local effect of the sea-ice east of Greenland on the southerly moisture transport. In cases of a large extent of sea-ice east of Greenland a large precipitationevaporation rate is found in the Greenland Sea which negatively impacts the net amount of water vapour transported towards Svalbard. Hence, the sea-ice east of Greenland Sea shields the west coast of Svalbard from the incoming southerly moisture transport. The composite analysis also indicates an eastward shift of the $500 \mathrm{hPa}$ geopotential anomaly fields, and hence the path way of moisture, during extreme events with high sea-ice coverage east 
of Greenland. Generally, our results are more robust when we use 'sea-ice coverage' instead of 'time' as a covariate for explaining the changes in extreme precipitation.

The initial research question guiding our study was whether the high frequency of extreme precipitation events observed in the past 8 years over the Svalbard Archipelago can be attributed to our warming climate. The analysis of the large ensemble of extreme events shows that indeed the magnitudes of extreme precipitation has been increasing over the last decades with a strong connection to the sea-ice decline east of Greenland.

\section{Acknowledgments}

The authors would like to thank Jana Sillmann and Rob Wilby for valuable discussions. MM was funded by the Research Council of Norway through the Nansen Legacy (NFR-276730) and the TWEX (NFR-255037) projects. TK was funded by the Loughborough University.

\section{References}

Cannon, A.J., Piani, C., Sippel, S., 2020. Chapter 5 - Bias correction of climate model output for impact models, in: Sillmann, J., Sippel, S., Russo, S. (Eds.), Climate Extremes and Their Implications for Impact and Risk Assessment. Elsevier, pp. 77 - 104. doi:https://doi.org/10.1016/B978-012-814895-2.00005-7.

Cohen, J., Screen, J.A., Furtado, J.C., Barlow, M., Whittleston, D., Coumou, D., Francis, J., Dethloff, K., Entekhabi, D., Overland, J., Jones, J., 2014. Recent Arctic amplification and extreme mid-latitude weather. Nat. Geosc. 7, 627-637. doi:https://doi.org/10.1038/ngeo2234.

Coles, S., Bawa, J., Trenner, L., Dorazio, P., 2001. An introduction to statistical modeling of extreme values. volume 208. Springer.

Dee, D.P., Uppala, S.M., Simmons, A.J., Berrisford, P., Poli, P., Kobayashi, S., Andrae, U., Balmaseda, M.A., Balsamo, G., Bauer, P., Bechtold, P., Beljaars, A.C.M., van de Berg, L., Bidlot, J., Bormann, N., Delsol, C., Dragani, R., Fuentes, M., Geer, A.J., Haimberger, L., Healy, S.B., Hersbach, H., Hólm, E.V., Isaksen, L., Kållberg, P., Köhler, M., Matricardi, M., McNally, A.P., Monge-Sanz, B.M., Morcrette, J.J., Park, B.K., Peubey, C., 
de Rosnay, P., Tavolato, C., Thépaut, J.N., Vitart, F., 2011. The ERAInterim reanalysis: configuration and performance of the data assimilation system. Q. J. R. Meteorol. Soc. 137, 553-597. doi:10.1002/qj.828.

Donlon, C.J., Martin, M., Stark, J., Roberts-Jones, J., Fiedler, E., Wimmer, W., 2012. The operational sea surface temperature and sea ice analysis (OSTIA) system. Remote Sens. Environ. 116, 140-158. URL: http://www.sciencedirect.com/science/article/pii/S0034425711002197.

Fichefet, T., Maqueda, M.A.M., 1997. Sensitivity of a global sea ice model to the treatment of ice thermodynamics and dynamics. J. Geophys. Res. 102, 12609-12646. doi:10.1029/97jc00480.

Gilleland, E., Katz, R.W., et al., 2016. extremes 2.0: an extreme value analysis package in R. J. Stat. Softw. 72, 1-39. doi:https://doi.org/10.18637/jss.v072.i08.

Hansen, B.B., Isaksen, K., Benestad, R.E., Kohler, J., Pedersen, A.O., Loe, L.E., Coulson, S.J., Larsen, J.O., Varpe, O., 2014. Warmer and wetter winters: characteristics and implications of an extreme weather event in the High Arctic. Env. Res. Lett. 9, 114021. doi:http://dx.doi.org/10.1088/1748-9326/9/11/114021.

Hersbach, H., de Rosnay, P., Bell, B., Schepers, D., Simmons, A., Soci, C., Abdalla, S., Alonso-Balmaseda, M., Balsamo, G., Bechtold, P., Berrisford, P., Bidlot, J.R., de Boisséson, E., Bonavita, M., Browne, P., Buizza, R., Dahlgren, P., Dee, D., Dragani, R., Diamantakis, M., Flemming, J., Forbes, R., Geer, A.J., Haiden, T., Hólm, E., Haimberger, L., Hogan, R., Horányi, A., Janiskova, M., Laloyaux, P., Lopez, P., Munoz-Sabater, J., Peubey, C., Radu, R., Richardson, D., Thépaut, J.N., Vitart, F., Yang, X., Zsótér, E., Zuo, H., 2018. Operational global reanalysis: progress, future directions and synergies with NWP. Technical Report 27. URL: https://www. ecmwf . int/node/18765, doi:10.21957/tkic6g3wm.

Hirahara, S., Alonso-Balmaseda, M., de Boisseson, E., Hersbach, H., 2016. Sea surface temperature and sea ice concentration for ERA5. ERA Report Series 26. European Centre for Medium-Range Weather Forecasts. Reading, UK. URL: https://www . ecmwf .int/en/elibrary/. 
Inoue, J., Hori, M.E., Takaya, K., 2012. The role of Barents sea ice in the wintertime cyclone track and emergence of a warm-arctic cold-siberian anomaly. J. Climate 25, 2561-2568, doi:10.1175/jcli-d-11-00449.1.

Johnson, S.J., Stockdale, T.N., Ferranti, L., Balmaseda, M.A., Molteni, F., Magnusson, L., Tietsche, S., Decremer, D., Weisheimer, A., Balsamo, G., Keeley, S.P.E., Mogensen, K., Zuo, H., Monge-Sanz, B.M., 2019. SEAS5: the new ECMWF seasonal forecast system. Geosc. Model Dev, 12, 10871117. doi:10.5194/gmd-12-1087-2019.

Kelder, T., Müller, M., Slater, L.J., Marjoribanks, T., Wilby, R.L., Prudhomme, C., Bohlinger, P., Ferranti, L., Nipen, T., 2020. Using UNSEEN trends to detect decadal changes in 100-year precipitation extremes. npj Clim. Atmos. Sci. 3,1-13.

Kim, B.M., Son, S.W., Min, S.K., Jeong, J.H., Kim, S.J., Zhang, X., Shim, T., Yoon, J.H., 2014. Weakening of the stratospheric polar vortex by Arctic sea-ice loss. Nat. Comm. 5, 4646. doi:https://doi.org/10.1038/ncomms5646.

Komatsu, K.K., Alexeev, V.A., Repina, I.A., Tachibana, Y., 2018. Poleward upgliding siberian atmospheric rivers over sea ice heat up arctic upper air. Scientific Reports 8, 2872. doi:https://doi.org/10.1038/s41598-018-211596 .

Lorenz, E., 1969. The predictability of a flow which possesses many scales of motion. Tellus A 21, 289-307. doi:10.1111/j.2153-3490.1969.tb00444.x.

Madec, G., et al., 2016. Nemo ocean engine. Note du Pôle de modélisation de l'Institut Pierre-Simon Laplace No 27, ISSN No 1288-1619.

Magnusdottir, G., Deser, C., Saravanan, R., 2004. The effects of North Atlantic SST and sea ice anomalies on the winter circulation in CCM3. Part i: Main features and storm track characteristics of the response. J. Climate 17, 857-876. doi:10.1175/1520-0442(2004).

Nash, D., Waliser, D., Guan, B., Ye, H., Ralph, F.M., 2018. The role of atmospheric rivers in extratropical and polar hydroclimate. J. Geophys. Res. Atmos. 123, 6804-6821. doi:10.1029/2017jd028130. 
Petoukhov, V., Semenov, V.A., 2010. A link between reduced Barents-Kara sea ice and cold winter extremes over northern continents. J. Geophys. Res. 115. doi:10.1029/2009jd013568.

Rinke, A., Maturilli, M., Graham, R.M., Matthes, H., Handorf, D., Cohen, L., Hudson, S.R., Moore, J.C., 2017. Extreme cyclone events in the Arctic: Wintertime variability and trends. Env. Res. Lett. 12, 094006. doi:http://dx.doi.org/10.1088/1748-9326/aa7def.

Rinke, A., Segger, B., Crewell, S., Maturilli, M., Naakka, T., Nygård, T., Vihma, T., Alshawaf, F., Dick, G., Wickert, J., Keller, J., 2019. Trends of vertically integrated water vapor over the Arctic during 1979-2016: Consistent moistening all over? J. Climate 32, 6097-6116. doi:10.1175/jcli-d19-0092.1.

Ruggieri, P., Buizza, R., Visconti, G., 2016. On the link between BarentsKara sea ice variability and European blocking. J. Geophys. Res. Atmos. 121, 5664-5679. doi:10.1002/2015jd024021.

Screen, J.A., Deser, C., Simmonds, I., Tomas, R., 2014. Atmospheric impacts of Arctic sea-ice loss, 1979-2009: separating forced change from atmospheric internal variability. Clim. Dynam. 43, 333-344. doi:https://doi.org/10.1007/s00382-013-1830-9.

Screen, J.A., Simmonds, I., 2010. The central role of diminishing sea ice in recent Arctic temperature amplification. Nature 464, 1334-1337. doi:https://doi.org/10.1038/nature09051.

Serreze, M.C., Crawford, A.D., Barrett, A.P., 2015. Extreme daily precipitation events at Spitsbergen, an Arctic Island. Int. J. Climatol. 35, 4574-4588. doi:10.1002/joc.4308.

Serreze, M.C., Stroeve, J., 2015. Arctic sea ice trends, variability and implications for seasonal ice forecasting. Philos. Trans. A Math Phys. Eng. Sci. 373.

Stroeve, J., Notz, D., 2018. Changing state of Arctic sea ice across all seasons. Env, Res. Lett. 13, 103001. doi:10.1088/1748-9326/aade56. 
Thompson, V., Dunstone, N.J., Scaife, A.A., Smith, D.M., Slingo, J.M., Brown, S., Belcher, S.E., 2017. High risk of unprecedented UK rainfall in the current climate. Nature communications 8, 107.

Titchner, H.A., Rayner, N.A., 2014. The Met Office Hadley Centre sea ice and sea surface temperature data set, version 2: 1 . Sea ice concentrations. J. Geophys. Res. Atmos. 119, 2864-2889. doi:10.1002/2013jd020316.

Vihma, T., 2014. Effects of Arctic sea ice decline on weather and climate: A review. Surv. Geophys. 35, 1175-1214. doi:https://doi.org/10.1007/s10712-014-9284-0.

Vihma, T., Screen, J., Tjernström, M., Newton, B., Zhang, X., Popova, V., Deser, C., Holland, M., Prowse, T., 2016. The atmospheric role in the Arctic water cycle: A review on processes, past and future changes, and their impacts. J. Geophys. Res. Biogeosci. 121, 586-620. doi:10.1002/2015jg003132.

Zhang, J., Tian, W., Chipperfield, M.P., Xie, F., Huang, J., 2016. Persistent shift of the Arctic polar vortex towards the Eurasian continent in recent decades. Nature Climate Change 6, 1094-1099. doi:https://doi.org/10.1038/nclimate3136.

Zuo, H., Alonso-Balmaseda, M.A., Mogensen, K., Tietsche, S., 2018. OCEAN5: The ECMWF Ocean Reanalysis System and its RealTime analysis component. Technical Report. ECMWF Tech. Memo. doi:doi.org/10.21957/la2v0442. 

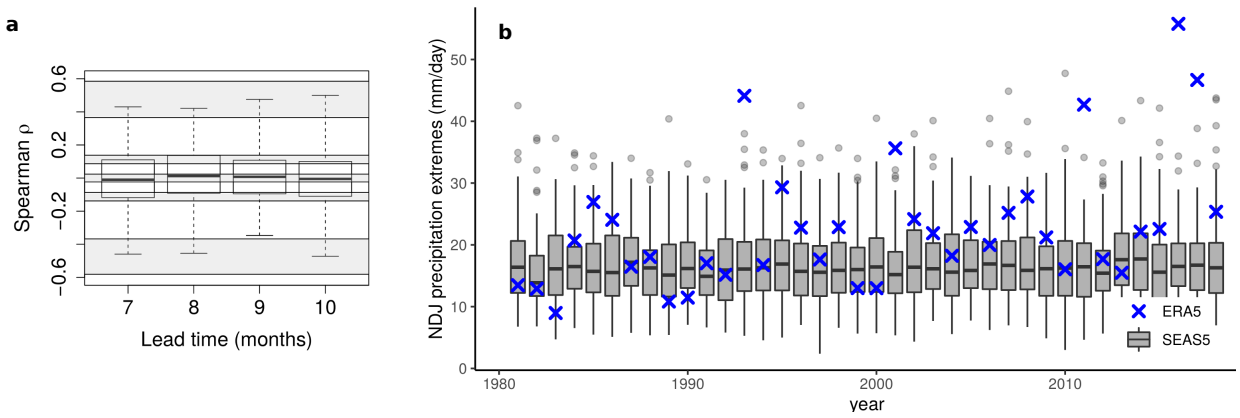

Figure 1: (a) The independence of SEAS5 extreme precipitation over Svalbard. Spearman's $\rho$ correlations for all distinct ensemble member pairs (300 in total) for each lead time, represented by boxplots. Grey shading shows the confidence intervals of the boxplot statistics (whiskers, interquartile range and median), based on a permutation test with $5 \%$ significance. (b) Seasonal (NDJ) extreme precipitation timeseries of ERA5 and SEAS5. The SEAS5 ensemble is shown by black boxplots representing the median, inter quartile range, whiskers (1.5 times the inter quartile range) and outliers (events outside the inter quartile range). The ERA5 precipitation maxima is denoted by blue $\mathrm{x}$. 
a

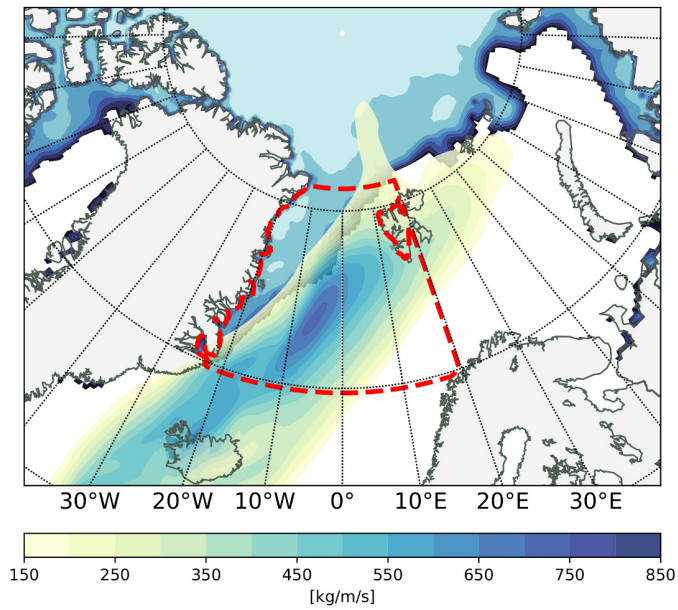

b

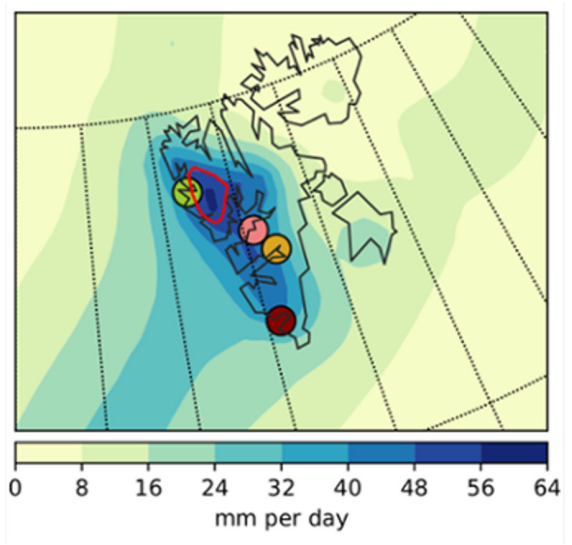

Figure 2: Observed Svalbard extreme precipitation event. (a) The IVT during the 7th November 2016 1200UTC. The red dashed line indicates the area for the calculation of the Greenland Sea sea ice extent. (b) The $24 \mathrm{~h}$ accumulated precipitation during the extreme precipitation event in 2016, the red line indicates the area used for the precipitation extreme analysis and corresponds to the $15 \mathrm{~mm} /$ day contour line of the $98 \mathrm{th}$ percentile of seasonal (NDJ) daily precipitation (ERA5) for the period from 1981 to 2018. 
a

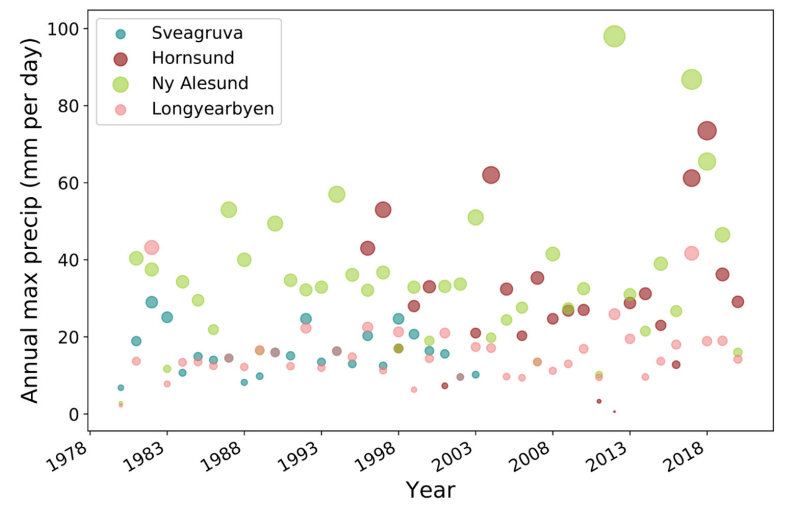

b

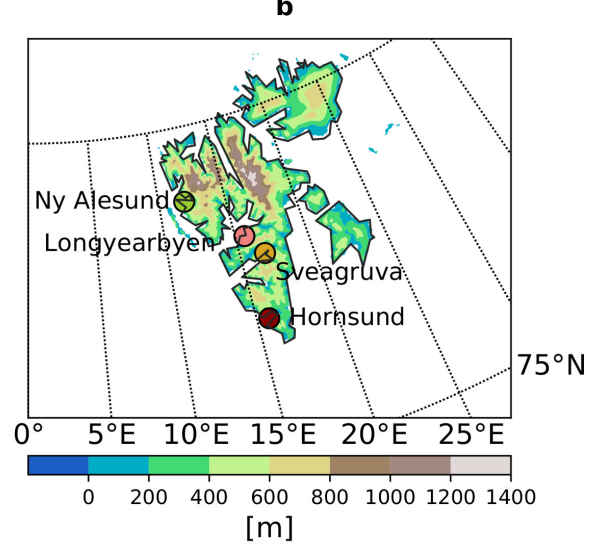

Figure 3: Observed extreme precipitation west Svalbard. (a) The seasonal (NDJ) maximum daily precipitation at four long-term observation sites. The size of the dots correspond to the precipitation amount. (b) The topography of the Svalbard Archipelago. The four observation sites are marked. 


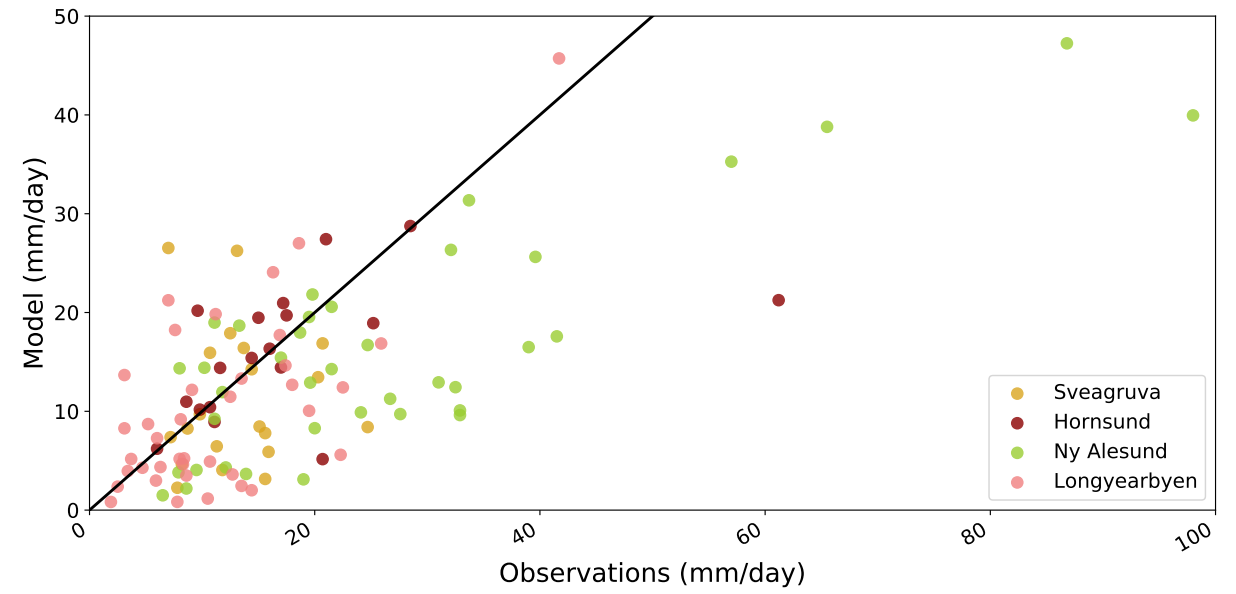

Figure 4: Comparison of seasonal (NDJ) maximum daily precipitation in ERA5 and observations. On the date the extremes are detected in the observations, the observed and the ERA5 precipitation are compared between 1981 and 2018. The black line indicates the 1-1 line. 

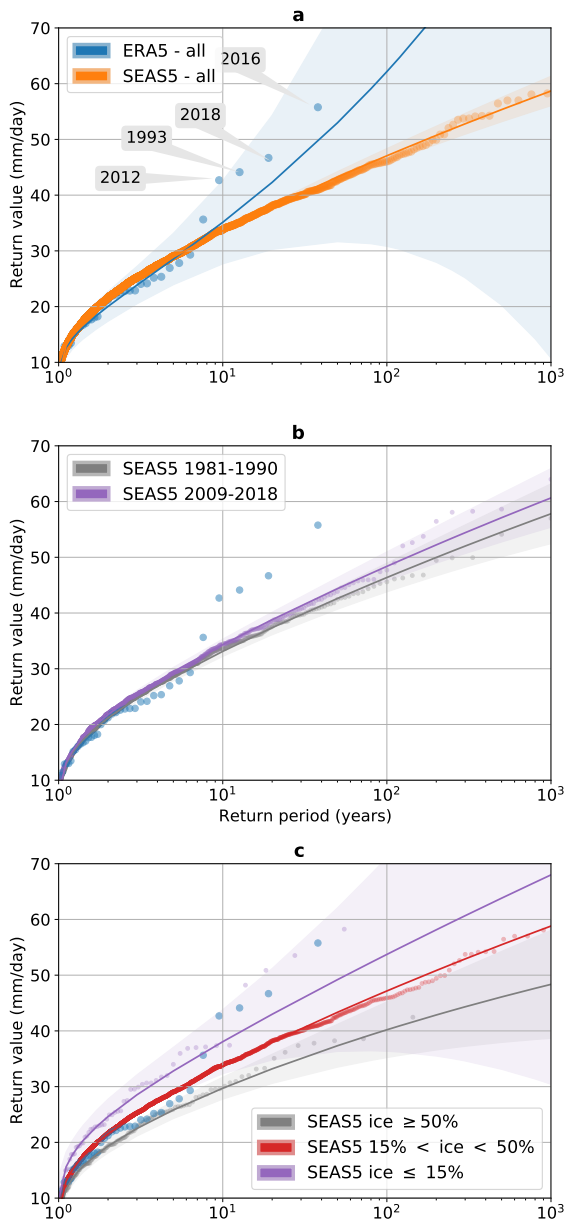

Figure 5: Return values and periods for extreme precipitation at the West Coast of Svalbard. (a) Obtained by the General Extreme Value (GEV) statistics the return values versus return periods for extreme precipitation in the northwest Svalbard region obtained from ERA5 (blue line) and SEAS5 realizations (orange line) are shown. The shaded areas indicating the $95 \%$ confidence intervals. The dots are indicating the actual data points following an empirical distribution. (b) Same as in (a) but for the SEAS5 realizations and subdivided into events between 1981-1990 and 2009-2018. (c) Same as in (a) but for the SEAS5 realizations and subdivided into events occurring for different states of the sea-ice east of Greenland. 
a

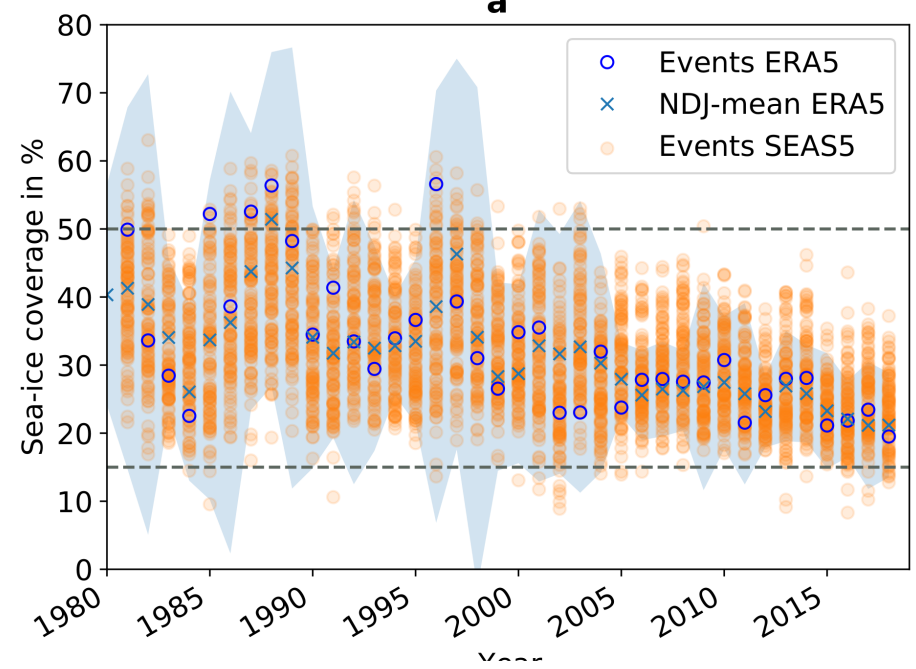

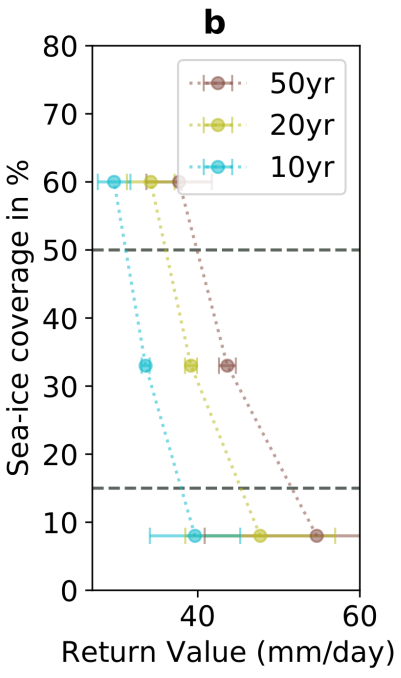

Figure 6: The sensitivity of extreme precipitation to the recent decline of precipitation. In (a) the mean sea-ice coverage of the Greenland Sea (region R1, blue crosses) and the $3 \sigma$ standard-deviation (blue shading) obtained from ERA5 are shown. Orange points indicate sea-ice coverage in SEAS5 during each of the precipitation extreme events (maximum precipitation in each NDJ season) and the blue circle indicates the sea-ice during the event in ERA5. In (b) precipitation return values (10, 20, and 50 years) for different percentages of sea-ice cover are shown. 

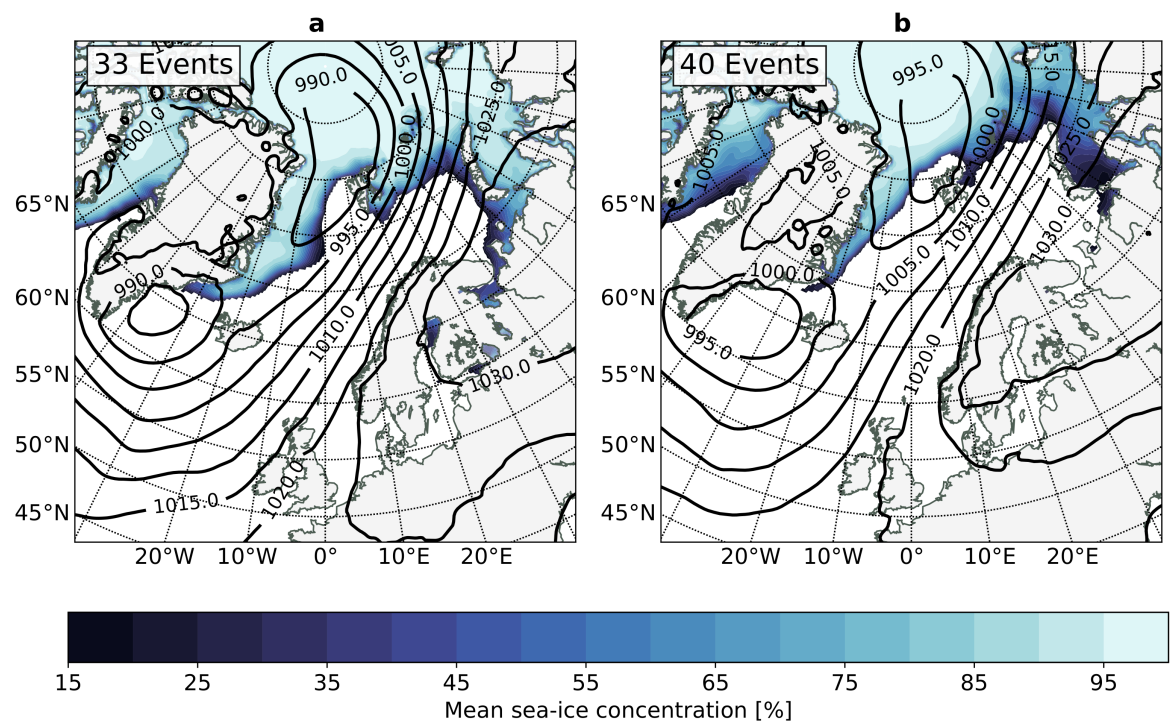

Figure 7: Composite maps of mean sea-level pressure and sea-ice concentration. All events are utilized with precipitation extremes exceeding the 20-year return value. The analysis for precipitation extremes in (a) for events with a sea-ice extent in the Greenland Sea larger than $50 \%$ and in (b) less than $20 \%$. 

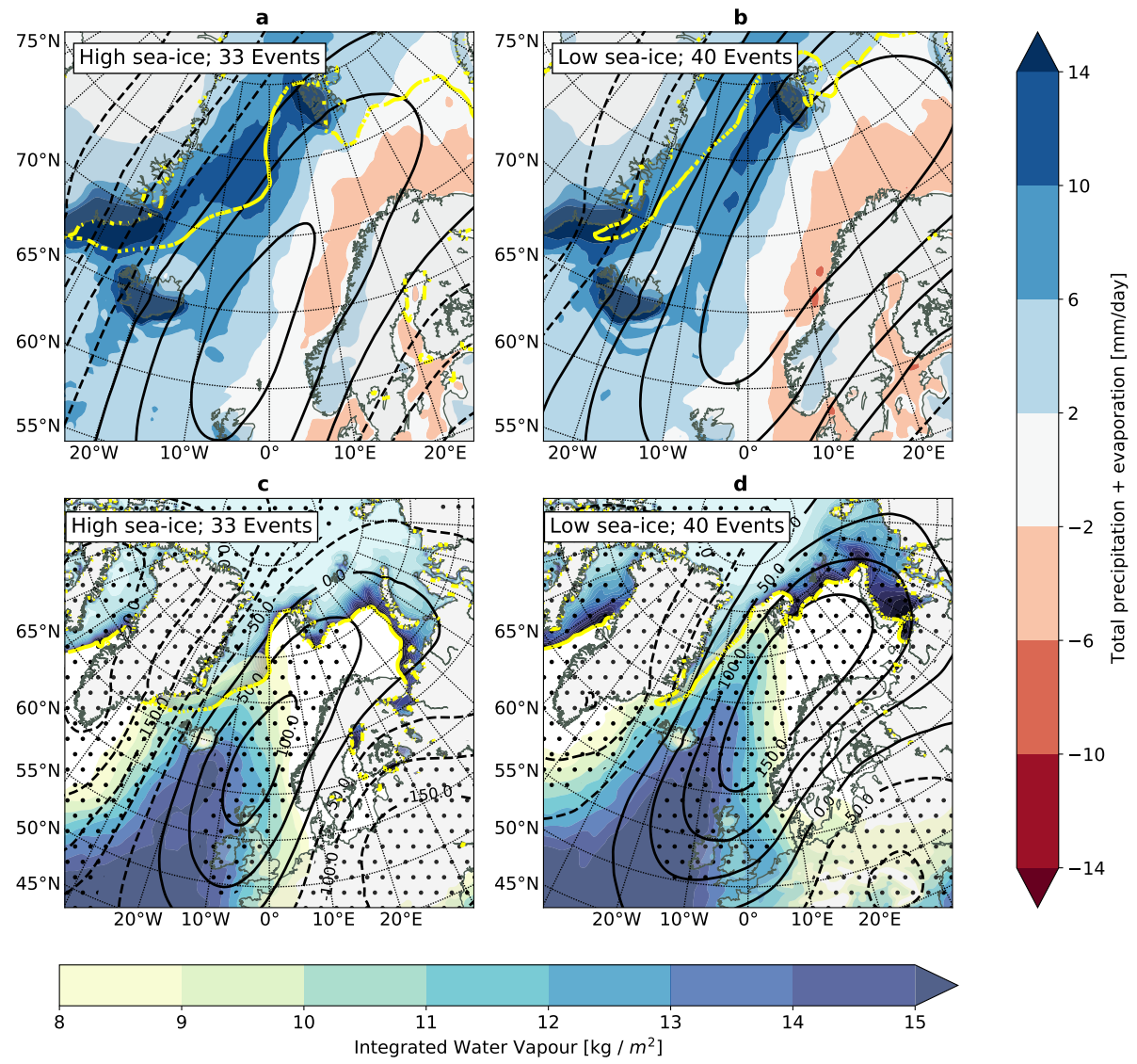

Figure 8: Atmospheric conditions of events with low and high sea-ice. All events with a return period higher than 20 years are used in this analysis. The analysis for precipitation extremes in the northwest region are shown in (a) for events with a sea-ice coverage of the Greenland Sea region larger than 50\% and in (b) less than 20\%. The number of events used for the composite analysis are indicated in the upper left corner of each sub-figure. The color contours represent the composite of 1-day precipitation (positive) + evaporation (negative). The thick yellow line indicates the $15 \%$ sea-ice concentration contour line. In (c) and (d) the same decomposition into high and low sea ice events as in (a) and (b), respectively, but the color-contoured field shows the vertically integrated water vapour. Grey dots indicate areas where the g500 anomalies are significant (student t-test 98\% confidence, tested with False Discovery Rate approach. 

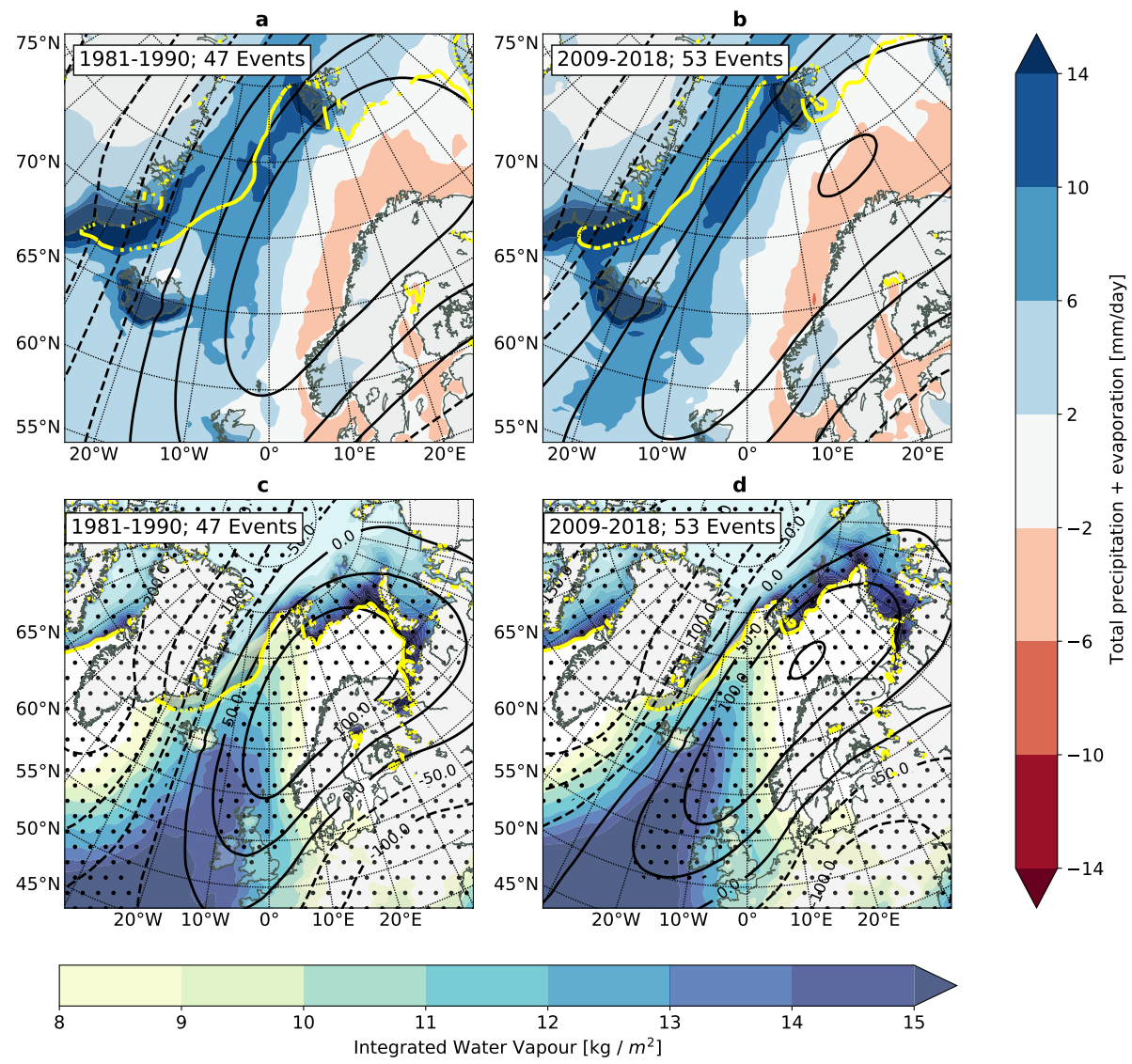

Figure 9: Atmospheric conditions of events in the 10 years before 1991 and after 2008. As in Figure 8 but for precipitation extremes events in (a) and (c) from 1981 to 1990 and in (b) and (d) from 2009 to 2018. 